\title{
Implementation of pharmacist-led medication reviews in general practice
}

\author{
Justin P. Turner $\cdot$ J. Simon Bell
}

Received: 28 September 2012/ Accepted: 22 October 2012/Published online: 6 November 2012

(C) Springer Science+Business Media Dordrecht 2012

Medication review conducted collaboratively by pharmacists and general medical practitioners (GPs) is a widely researched strategy to optimise medication use [1-3]. Home Medicines Review (HMR) is an Australian government funded collaborative medication review service for people living independently in the community. This service has traditionally involved a GP referring a patient to their preferred community pharmacy, which in turn arranges a pharmacist to conduct the review. In October 2011, an additional referral pathway was introduced. Rather than referring to a community pharmacy, GPs may now refer directly to an HMR accredited pharmacist. In this issue, Freeman et al. [4] describe an innovative practice model, consistent with this new referral pathway, in which an accredited 'practice-pharmacist' works in a GP medical practice.

Despite the exploratory nature of the study, a number of benefits were apparent. Firstly, the 'practice-pharmacist' completed over 300 HMRs in a year period compared to an average of approximately 10 HMRs per year under the alternative 'external-pharmacist' model. Increased uptake and timeliness of HMRs is likely to have public health benefits $[5,6]$. A recent study reported just $5.5 \%$ of patients at high risk of ADEs received an HMR [5]. Secondly, while the 'practice-pharmacist' identified fewer drug-related problems per patient than the 'external-pharmacist' (3.6 vs. 5.4), a higher percentage of recommendations made by the 'practice-pharmacist' was implemented

J. P. Turner · J. S. Bell ( $($ )

Quality Use of Medicines and Pharmacy Research Centre, Sansom Institute, School of Pharmacy and Medical Sciences, University of South Australia, GPO Box 2471, Adelaide, SA 5001, Australia

e-mail: simon.bell@unisa.edu.au by the referring GP (71 vs. $53 \%$ ). As suggested by the authors, access to patients' medical records while undertaking the review may have ensured recommendations were more relevant to clinical care. Greater rapport resulting from integration of the 'practice-pharmacist' into the GP team may have also contributed to higher rates of recommendation implementation. Thirdly, the model described by Freeman et al. provided ample opportunities for face-to-face post HMR discussion between the pharmacist and GP. Post HMR case conferences were included in much of the original Australian research on which implementation of the HMR service was based [7, 8].

An issue not explored by Freeman et al. was the reasons for non-acceptance of the pharmacists' recommendations. Reasons for non-acceptance of the pharmacists' recommendations may have included patients' preference not to alter their medication regimen, GPs having greater knowledge of patients' therapeutic goals, or psychological reactance among GPs [9]. A further issue not explored was whether the nature of the findings and recommendations made by the 'practice-pharmacist' changed over time. Recommendations for one patient might have been extrapolated to others. Working in the practice may have meant that the pharmacist's HMR recommendations became more aligned with the needs and expectations of GPs. The pharmacist may have been also able to identify and act upon practice-level prescribing issues.

In the model described by Freeman et al. the patient was able to choose the location of the HMR, either in their home or the GP medical practice. Interestingly, the location of the HMR had little impact on the types of HMR recommendations. The home visit is widely considered a key component of the review process. It provides an opportunity to check medication storage, remove expired medication, and to compile a complete medication list (e.g. 
including non-prescribed medications) [10]. Anecdotally there are patients (e.g. those with dementia) who particularly benefit from the home visit. The findings of Freeman et al. suggest that further research is warranted to investigate the added value of routinely offering the home visit to all HMR recipients.

Given that the research by Freeman et al. involved one pharmacist and one GP medical practice the generalisability of the findings are unknown. GP referral to a patient's preferred community pharmacy and pharmacist home visit will continue to be viewed as the 'gold standard' by many. Nevertheless, the continued high rates of preventable ADEs, particularly among older people, suggest that initiatives like this fulfil an important need [11]. Previous research has shown support for this model among GPs and pharmacists in Australia and Canada [12-14]. Freeman et al. provide an example of how it is possible for pharmacists to work within the framework of a national program to innovate at a local level.

\section{References}

1. Stafford L, Stafford A, Hughes J, Angley M, Bereznicki L, Peterson G. Drug-related problems identified in post-discharge medication reviews for patients taking warfarin. Int J Clin Pharm. 2011;33:621-6.

2. Kaae S, Sørensen EW, Nørgaard LS. Exploring communications around medication review in community pharmacy. Int $\mathrm{J}$ Clin Pharm. 2011;33:529-36.

3. Nishtala PS, McLachlan AJ, Bell JS, Chen TF. A retrospective study of drug-related problems in Australian aged care homes: medication reviews involving pharmacists and general practitioners. J Eval Clin Pract. 2011;17:97-103.
4. Freeman CR, Cottrell WN, Kyle G, Williams I, Nissen L. An evaluation of medication review reports across different settings. Int J Clin Pharm. 2012; in press.

5. Lee CY, George J, Elliott RA, Stewart K. Prevalence of medication-related risk factors among retirement village residents: a cross-sectional survey. Age Ageing. 2010;39:581-7.

6. Peterson GM, Jackson SL, Naunton M. Home medicines review in the elderly: most effective if performed and reported in a timely manner. Aust Pharm. 2006;30:860-3.

7. Krass I, Smith C. Impact of medication regimen reviews performed by community pharmacists for ambulatory patients with general medical practitioners. Int J Pharm Pract. 2000;8:111-20.

8. Gilbert AL, Roughead EE, Beilby J, Mott K, Barratt JD. Collaborative medication management services: improving patient care. Med J Aust. 2002;177:189-92.

9. de Almeida Neto AC, Chen TF. When pharmacotherapeutic recommendations may lead to the reverse effect on physician decision-making. Pharm World Sci. 2008;30:3-8.

10. Sorensen L, Stokes JA, Purdie DM, Woodward M, Roberts MS. Medication management at home: medication risk factor prevalence and inter-relationships. J Clin Pharm Ther. 2006;31: 485-91.

11. Kalisch LM, Caughey GE, Barratt JD, Ramsay EN, Killer G, Gilbert AL, et al. Prevalence of preventable medication-related hospitalizations in Australia: an opportunity to reduce harm. Int J Qual Health Care. 2012;24:239-49.

12. Freeman C, Cottrell WN, Kyle G, Williams I, Nissen L. Integrating a pharmacist into the general practice environment: opinions of pharmacist's, general practitioner's, health care consumer's, and practice manager's. BMC Health Serv Res. 2012;212:229.

13. Farrell B, Pottie K, Haydt S, Kennie N, Sellors C. Integrating into family practice: the experiences of pharmacists in Ontario. Can Int J Pharm Pract. 2008;16:309-15.

14. Pottie K, Farrell B, Haydt S, Dolovich L, Sellors C, Kennie N, et al. Integrating pharmacists into family practice teams: physicians' perspectives on collaborative care. Can Fam Physician. $2008 ; 54: 1714-7$. 